\title{
Synthesis of A Sulfur-Graphene Composite as An
}

\section{Enhanced Metal-free Photocatalyst}

Wen-chao Peng and Xiao-yan $\mathrm{Li}^{*}$

\section{Environmental Engineering Research Centre,}

Department of Civil Engineering, The University of

Hong Kong, Pokfulam, Hong Kong

${ }^{*}$ Corresponding author. Tel: (852)28592659, Fax: (852)25595337. E-mail: xlia@hkucc.hku.hk

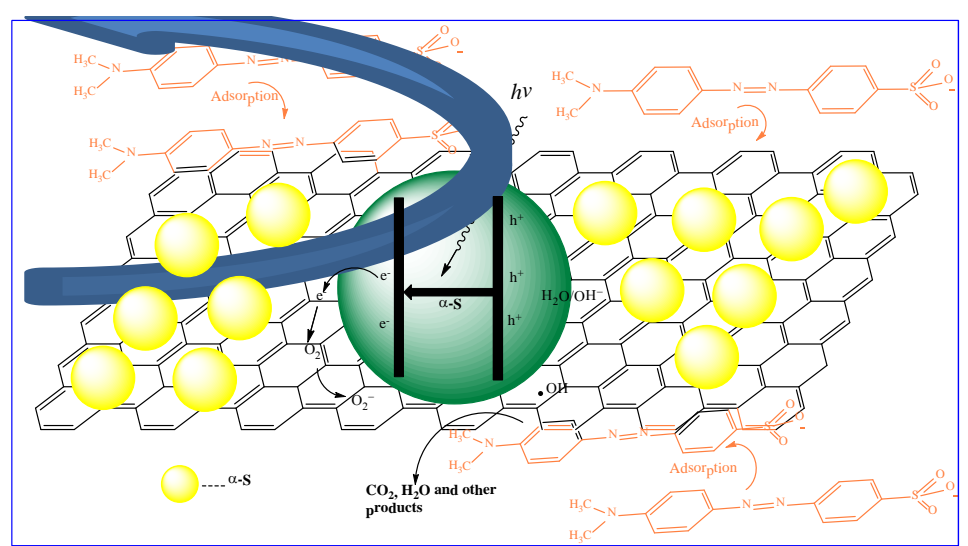

A novel metal-free photocatalyst, sulfur/graphene (S/GR) composite, was synthesized using a facial, one-pot hydrothermal method. The composite showed good activity for the photocatalytic degradation of methyl orange under both UV and solar light. 


\title{
Synthesis of A Sulfur-Graphene Composite as An Enhanced Metal-free Photocatalyst
}

\author{
Wen-chao Peng, and Xiao-yan Li $(\bowtie)$ \\ Environmental Engineering Research Centre, Department of Civil Engineering, The University of Hong Kong, Pokfulam, Hong \\ Kong \\ Received: day month year / Revised: day month year / Accepted: day month year (automatically inserted by the publisher) \\ (C) Tsinghua University Press and Springer-Verlag Berlin Heidelberg 2011
}

\begin{abstract}
A novel metal-free photocatalyst, sulfur/graphene (S/GR) composite, was synthesized using a facial one-pot, two-step hydrothermal method with thiosulfate and graphene oxide (GO) as precursors. A green reductant l-ascorbic acid was used to transform GO to GR under a mild condition. The photocatalyst powders were characterized by the fourier transform infrared spectroscopy, X-ray diffraction, transmission electron microscopy, scanning electron microscopy, and energy dispersive spectroscopy. Experimental tests were conducted on the photocatalytic decomposition of methyl orange (MO) by the different catalysts. Compared to pure $\alpha$-S, the as-prepared S/GR composite showed much enhanced photocatalytic activity for the degradation of $\mathrm{MO}$ under both UV and solar light The GR addition also greatly increased the hydrophilicity and adsorption capacity of the catalyst material. The results indicate that the incorporation of GR with $\alpha$-S results in a synergistic effect on the S-based photocatalysts for more effective environmental applications.
\end{abstract}

\section{KEYWORDS}

Metal-free catalyst, $\alpha$-Sulfur, Graphene, Photocatalysis, Methyl orange, Organic degradation

\section{Introduction}

The photocatalysis field has been dominated by metal-based materials owing largely to band-gap limitations. A number of metal oxides, metal sulfates, and salts are known to have good photoactivities under UV or visible light [1]. To develop more effective and environmentally friendly photocatalysts, efforts have been made in recent years to apply non-metal materials in the synthesis of new photocatalysts. Silica QDs, red phosphorus, $\alpha$-sulfur $(\alpha-S)$, and a polymer g- $_{3} \mathrm{~N}_{4}$ are reported to be active for organic photocatalysis or water splitting reactions [2-5]. Among these new metal-free catalysts, $\alpha$-S shows a great potential owing to its simple facial preparation, good photo-sensitivity with a narrow band-gap $(2.79 \mathrm{eV})$, and high stability [4]. However, in view of its poor hydrophilicity and low reactivity, improvement is 
still needed for $\alpha-S$ to greatly increase its functionality and efficiency in photocatalytic application [4].

Graphene (GR), a versatile carbon material with a single layer and $\mathrm{sp}^{2}$-hybridized carbon lattice, possesses excellent electrical, thermal, and mechanical properties [6]. GR has been increasingly used as a support for metals or metal oxides in the fabrication of new catalysts with much enhanced activity [7]. GR is also a new star material in the photocatalysis field, which can serve as an excellent charge carrier at room temperature (200 000 $\mathrm{cm}^{2} \mathrm{~V}^{-1} \mathrm{~s}^{-1}$ ) [8]. Thus, by incorporating GR to form electron-conducting surfaces and channels, the photocatalytic activity of the composite materials can be greatly increased, mainly owing to the effective suppression of the recombination of photo-generated electron-hole pairs [8,9]. Significant improvement has been reported for metal oxides, metal sulfates, and non-metal g- $\mathrm{C}_{3} \mathrm{~N}_{4}$ by using GR as a synergistic catalyst material $[8,10,11]$. However, there has been no report on the modification of $\alpha$-S with GR for making new photocatalysts. In this study, we integrated a small percentage $(\leq 3 \%)$ of GR into $\alpha$-S to fabricate a new metal-free photocatalyst. With the synergistic function of GR, the catalytic activity of $\alpha-S$ was greatly enhanced for the photocatalytic degradation of methyl orange (MO) under both UV and simulated solar (SS) light. Moreover, compared with $\alpha-S$, the S/GR composite is more modifiable because of its better hydrophilicity and new functional groups, thus other novel photocatalysts can be prepared from the S/GR composite.

\section{Materials and Methods}

\subsection{Preparation of graphite oxide}

Hummer's method was used to synthesize graphite oxide from graphite powder [12]. Briefly, graphite ( $2 \mathrm{~g}$ ) was mixed with $\mathrm{NaNO}_{3}(1 \mathrm{~g})$ in $50 \mathrm{~mL}$ concentrated $\mathrm{H}_{2} \mathrm{SO}_{4}(98 \%)$ at $0{ }^{\circ} \mathrm{C}$, and $\mathrm{KMnO}_{4}(6 \mathrm{~g})$ was then added gently into the system. After being kept at $0^{\circ} \mathrm{C}$ for $2 \mathrm{~h}$, the mixture was stirred at room temperature for $30 \mathrm{~min}$. Deionized (DI) water (100 $\mathrm{mL}$ ) was slowly added into the system, while the temperature was kept at $95-98^{\circ} \mathrm{C}$ for $3 \mathrm{~h}$. The mixture was further treated with $5 \% \mathrm{H}_{2} \mathrm{O}_{2}(50 \mathrm{~mL})$ for $1 \mathrm{~h}$. Finally, graphite oxide formed in the suspension was filtered and washed with DI water, which was then dried at $60^{\circ} \mathrm{C}$ for $2 \mathrm{~d}$.

\subsection{Synthesis of sulfur-graphene (S/GR) composites}

Graphite oxide was first exfoliated into graphene oxide (GO) by sonication in DI water [13]. Typically, $24.8 \mathrm{~g}(0.1 \mathrm{~mol}) \quad \mathrm{Na}_{2} \mathrm{~S}_{2} \mathrm{O}_{3} \cdot 5 \mathrm{H}_{2} \mathrm{O}$ was charged into $100 \mathrm{~mL}$ of $\mathrm{GO}$ solution at a predetermined concentration (e.g. $0.8 \mathrm{mg} / \mathrm{mL}$ for S/GR-1\%). The mixture was sonicated for $30 \mathrm{~min}$ followed by stirring for $30 \mathrm{~min}$ to form a homogenous solution. The solution $\mathrm{pH}$ was then adjusted and kept at $\sim 2.0$ by adding $\mathrm{H}_{2} \mathrm{SO}_{4}(30 \%)$ every $30 \mathrm{~min}$ for $2 \mathrm{~h}$ to precipitate sulfur on the surface of the GO. Subsequently, $1.0 \mathrm{~g}$ L-ascorbic acid (AA) was added to reduce the GO to graphene (GR). After adjusting the $\mathrm{pH}$ to $\sim 9.5$ with $\mathrm{NaOH}(5$ $w \mathrm{t} \%)$, the solution was heated to $85^{\circ} \mathrm{C}$ for $4 \mathrm{~h}$. After cooling to room temperature, the S/GR composite formed in the solution was washed with DI water and then dried in vacuum at $85^{\circ} \mathrm{C}$ in an oven. Around $0.5 \mathrm{mg}$ of GR can be generated from $1 \mathrm{mg}$ of GO after the AA reduction. Pure sulfur crystals were synthesized following the same procedure as described above for the S/GR composites, except for the addition of GO into the $\mathrm{Na}_{2} \mathrm{~S}_{2} \mathrm{O}_{3}$ solution and the subsequent reduction process.

\subsection{Photocatalytic degradation of methyl orange (MO)}

Photodecomposition of methyl orange (MO) was performed in a photo-reactor. For a typical test, 
$50 \mathrm{mg}$ of photocatalyst was first dispersed in $50 \mathrm{~mL}$ of water in a quartz photo-tube by sonication, followed by the addition of $\mathrm{MO}$ to an initial concentration of $20 \mathrm{mg} / \mathrm{L}$. Before exposure to light, the suspension was stirred in the dark to allow adsorption of $\mathrm{MO}$ by the catalyst powders. According to the color measurement by a UV-vis spectrophotometer (Perkin, Lamda 25), the MO adsorption by the catalysts achieved equilibrium within $30 \mathrm{~min}$. For photocatalysis of MO in an XPA photo-reactor (Xujiang Electromechanical Plant, Nanjing, China), the light source was either a $300 \mathrm{~W}$ high pressure mercury lamp for UV light or a $500 \mathrm{~W}$ xenon lamp for the simulated solar (SS) light. During the photocatalytic process, $4 \mathrm{~mL}$ of the solution was sampled from each photo-tube at regular intervals to monitor the MO concentration change. The sample was withdrawn through a syringe filter $(0.2 \mu \mathrm{m})$ and the absorbance (ABS) of the filtrate was measured at $463 \mathrm{~nm}$ by the UV-visible spectrophotometer as an indication of the MO concentration in the solution.

\subsection{Material characterization}

The X-ray diffraction (XRD) patterns of the photocatalyst materials were analyzed for their crystal forms by a Bruker D8 Advance X-ray powder diffractometer. The morphology of the catalysts was examined by scanning electron microscopy (SEM) (Hitachi S-4800 FEG SEM, Tokyo, Japan) and transmission electron microscopy (TEM) (Philips Tecnai G220 S-TWIN, Amsterdam, the Netherlands). Fourier transform infrared spectroscopy (FT-IR) (Perkin Elmer, FT-IR Spectrophoeometer Spectrum One B) was used for characterization of the functional groups of different catalysts.

\section{Results and Discussion}

\subsection{Characterization of the photocatalysts}

The $\alpha$-S/GR composites were prepared following a facial one-pot, two-step hydrothermal method. Typically, the graphene oxide (GO) and sodium thiosulfate at a predetermined ratio were dissolved in DI water with sonication to form a homogenous solution [14]. The solution $\mathrm{pH}$ was adjusted to $\sim 2$, resulting in an $S$ precipitate that deposited on the surface of the GO to form S/GO. Then, 1-ascorbic acid (AA) was added to reduce the $\mathrm{S} / \mathrm{GO}$ to $\mathrm{S} / \mathrm{GR}$ at $85^{\circ} \mathrm{C}$. AA was selected here for its suitable reducibility and non-toxicity [15].

FT-IR was used to analyze the change in functional groups during the synthesis process (Figure 1a). Pure GR was obtained by the reduction of GO with AA under the same conditions but without the presence of sodium thiosulfate. Abundant oxygen-containing groups can be identified from the FT-IR spectrum of GO, e.g. 1630 $\mathrm{cm}^{-1}$ for COO, $1392 \mathrm{~cm}^{-1}$ for O-H, and $1085 \mathrm{~cm}^{-1}$ for $\mathrm{C}-\mathrm{O}$ groups, which provide active sites for sulfur precipitation. As shown by the spectrum of GR, almost all of the functional groups were removed by $\mathrm{AA}$ reduction in the absence of thiosulfate, indicating the effectiveness of AA for the reduction of GO to GR. With the addition of thiosulfate during the synthesis process, a few new functional groups were produced on the resulting S/GR composite, which appeared to be stable even after the AA reduction. $\mathrm{C}=\mathrm{S}$ stretching $\left(1220 \mathrm{~cm}^{-1}\right)$ and C-S stretching $\left(1098 \mathrm{~cm}^{-1}\right)$ can be found in the spectrum of $S / G R$, indicating that $S$ particles are chemically bonded to the GR sheets [14]. These chemical bonds are important to the stability of the S/GR composite. 

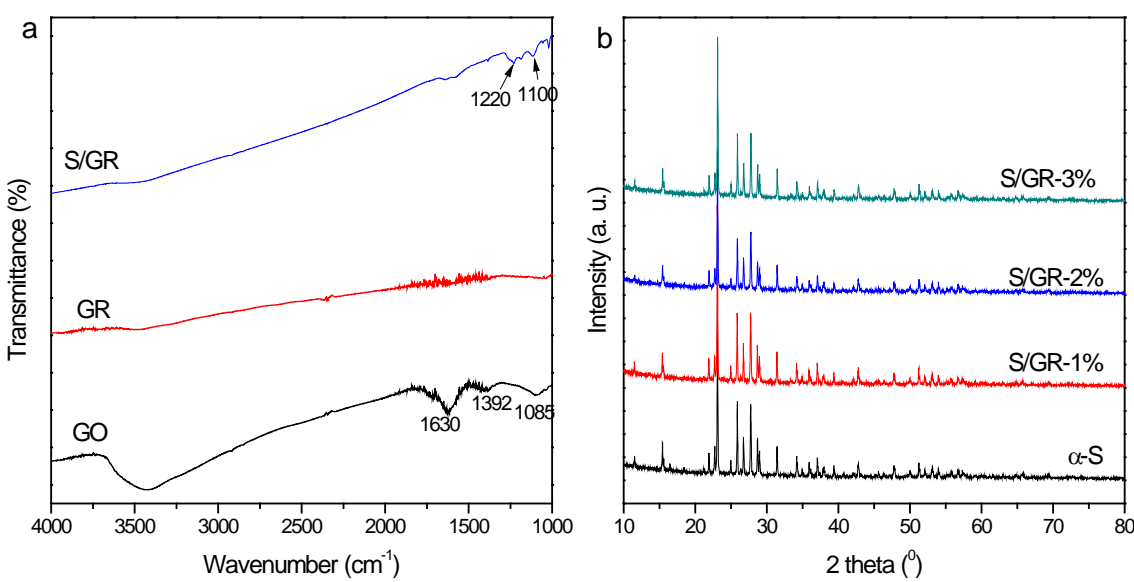

Figure 1 (a) FT-IR profiles of GO, GR, and S/GR composite; (b) XRD patterns of pure $\alpha$-S and S/GR powders.

XRD analysis was also conducted to determine the crystal form of sulfur (Figure 1b). Typical reflections of $\alpha$-octa-sulfur (S8, JCPDS\#08-0247) were clearly observed for the pure $S$ particles $[4,14]$. The crystal form of $\alpha$-S was not affected by the incorporation of GR at different percentages, thus ensuring the photocatalytic activity of $\alpha$-S in the S/GR composites. No characteristic GR diffraction peaks could be clearly identified from the XRD pattern of $S / G R$, which might be due to the low amount $(\leq 3 \mathrm{wt} \%)$ of GR added and its low diffraction intensity [16].

Figure 2 shows the morphologies of the $\alpha$-S and S/GR composites at different magnifications. The pure $S$ crystals generally appear to be solid spheres with a diameter as large as 2-3 $\mu \mathrm{m}$, probably formed by the agglomeration of primary $S$ particles. The addition of GO was shown to decrease the size of $S$ particles. It is apparent that the presence of abundant oxygen-containing groups on the GO surface increased the number of active sites for $S$ precipitation. After the reduction with AA, GO was reduced to GR, and smaller $S$ particles $(\sim 1 \mu \mathrm{m})$ were found to attach firmly on the GR surface (Figure $2 b-c)$. While the SEM image of S/GR shows only the morphologies of $\mathrm{S}$ particles (Figure $2 b$ ), both $S$ and GR can be observed from the TEM image (Figure 2c). Despite the small percentage of GR, free GR can still be found at the edge of the S-based composite. Figure $2 \mathrm{~d}$ at a higher magnification shows the TEM image of free GR at the edge of the composite, in which the typical morphology of chemically reduced GR with obvious wrinkles can be found. The elemental composition of the S/GR composite was further confirmed by the EDS and elemental analyses. Figure 3 presents the elemental mapping results for $\mathrm{S}$ and $\mathrm{C}$ in the $\mathrm{S} / \mathrm{GR}$ composite in a selected region (Figure 3a). The yellow dots in Figure $3 b$ indicate sulfur, while the white dots in Figure $3 \mathrm{c}$ are carbon. The elemental mapping results confirm that GR was uniformly dispersed over the S/GR composite. 


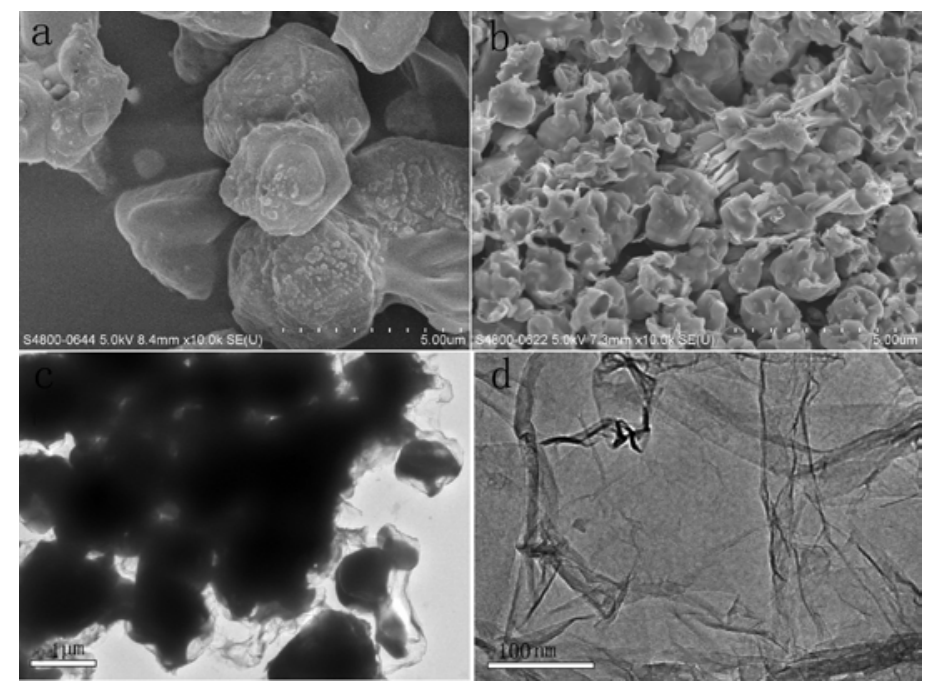

Figure 2 (a) SEM image of pure -S particles, (b) SEM image of the S/GR composite, (c) TEM image of S/GR, and (d) TEM image of GR at the edge of S/GR composite.

Pure $\alpha$-S has poor hydrophilicity and a low adsorption capacity, which is partially responsible for its low photoactivity in the aqueous phase [4]. The incorporation of GR can greatly improve the hydrophilicity of $\alpha$-S. Figure 4 displays the dispersion of $S / G R$ composites in water in comparison to $\alpha$-S particles. While the pure $\alpha$-S would only stay on top of the water, the S/GR powders could be readily dispersed in water, with sonication of $15 \mathrm{~min}$ or so. This increase in hydrophilicity can greatly improve the functionality of the S/GR composites in photocatalysis applications.

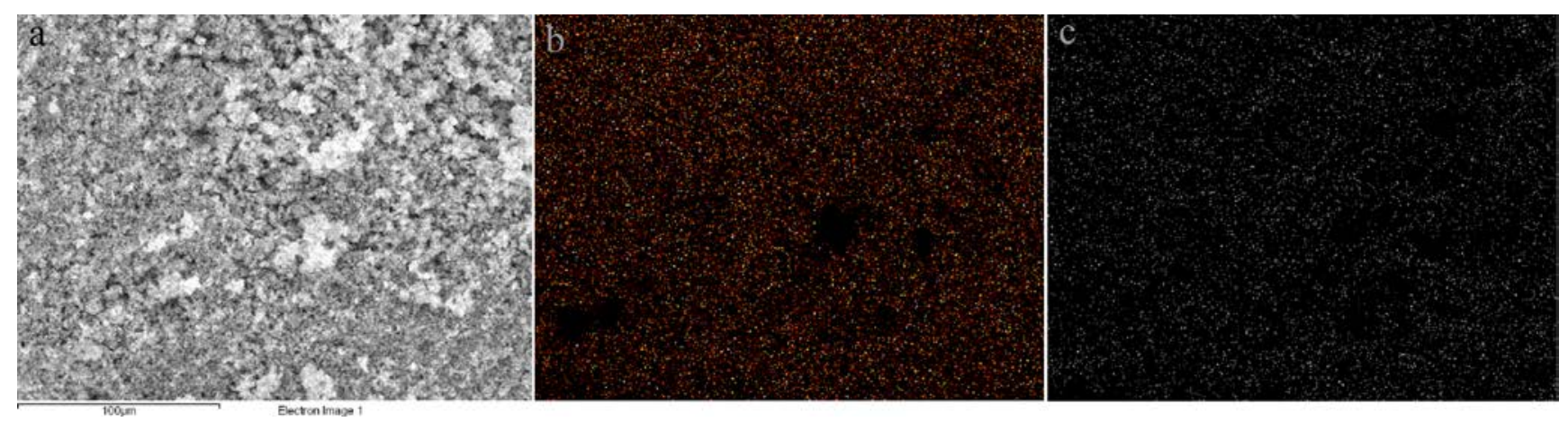

Figure 3 Elemental analysis and $\mathrm{N}_{2}$-adsorption results for the S/GR-3\% composite: (a) SEM image of the mapping area, (b) sulfur $\mathrm{K} \alpha$ mapping, and (c) carbon K $\alpha$ mapping. 


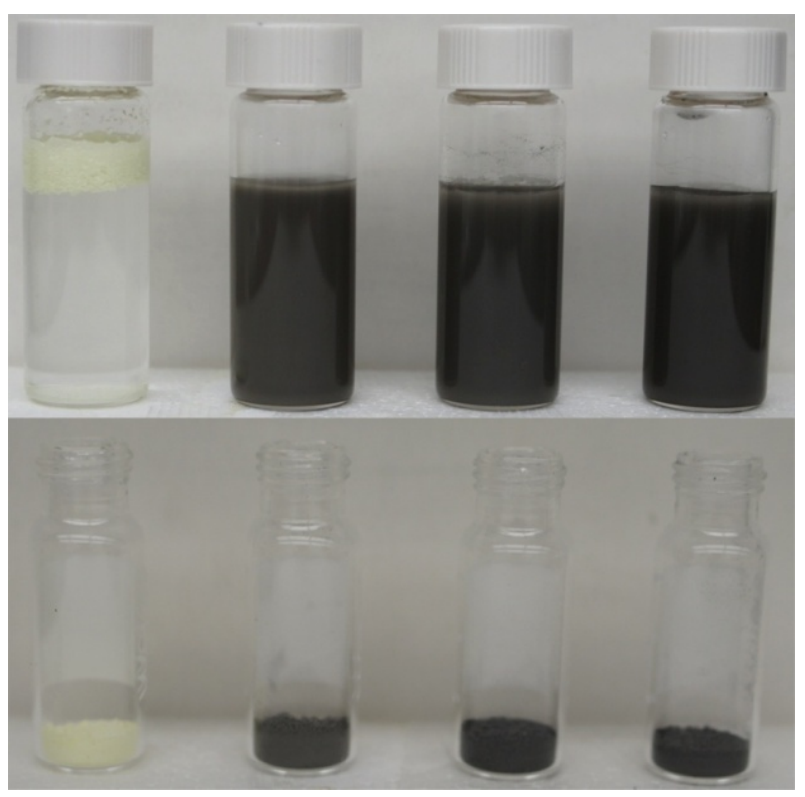

Figure 4 The catalyst powders and suspensions: bottom photo (from left to right) - dry powders of $\alpha$-S, S/GR-1\%, S/GR-2\%, and S/GR-3\%; top photo - the suspensions of the catalysts in water after sonication

The photocatalytic activities of different catalysts were tested for the degradation of methyl orange (MO), one of the important classes of commercial dyes. MO has often been used as a model dye to test photoredox reactions for decoloring due to the short life of its excited-state and high stability under visible and near UV light [17]. The catalysts with a dosing density of $1 \mathrm{mg} / \mathrm{mL}$ were first dispersed in water by sonication, and $\mathrm{MO}$ was then added at an initial concentration of 20 $\mathrm{mg} / \mathrm{L}$ in the photo-tubes. Before exposure to light, the suspensions were stirred in the dark for $30 \mathrm{~min}$ to allow MO adsorption by the catalysts. Based on the color comparison in Figure 5, the adsorption capability of the catalysts clearly increased with the addition of GR to the composites. This should be due to the chemical adsorption capacity brought about by the GR and the hydrophilic surface of the catalyst powders after the modification.

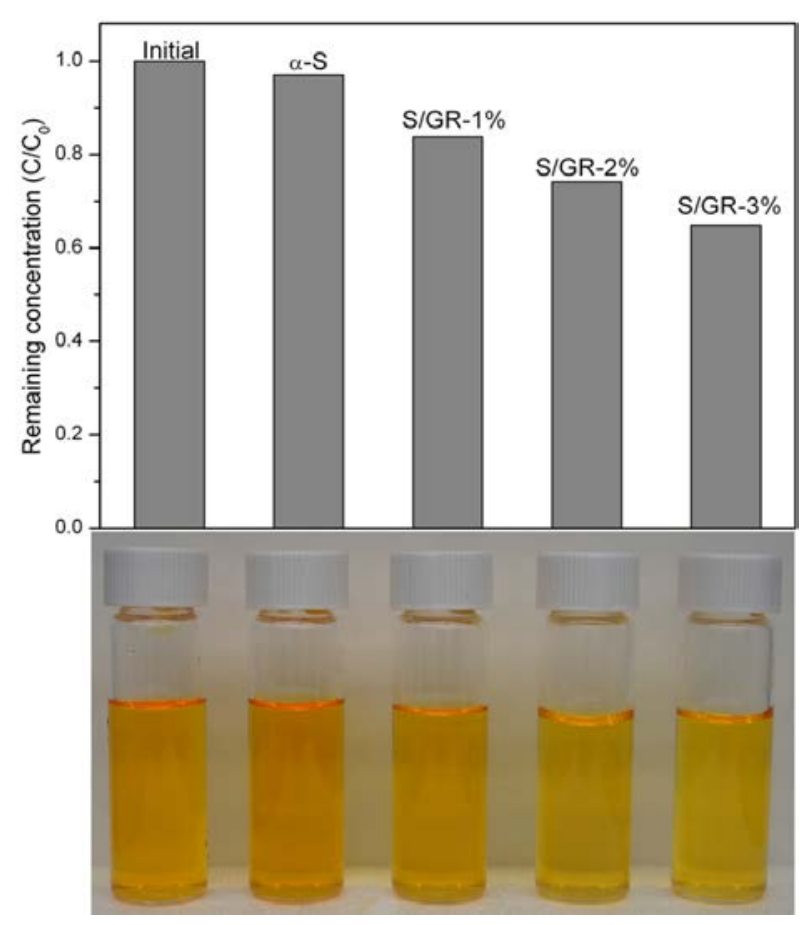

Figure 5 Change of the MO concentration after adsorption by different catalyst materials: top chart - the resulting MO reduction in the solutions; the bottom photo - the appearance of the MO solutions after 30-min adsorption in the dark.

The reductions in $\mathrm{MO}$ during the degradation experiments with different photocatalysts are presented in Figure 6, in which $\mathrm{C}_{0}$ corresponds to the absorbance (ABS) at $463 \mathrm{~nm}$ of $\mathrm{MO}$ at its original concentration $(20 \mathrm{mg} / \mathrm{L})$ and $\mathrm{C}$ corresponds to the ABS of MO after a specified test period. The results show that the addition of a small amount of GR can greatly enhance the photocatalytic activity of $\alpha$-S under both UV and solar radiations. After 3 $\mathrm{hr}$, the S/GR-3\% composite in the solution reduced the $\mathrm{MO}$ by around $83 \%$ and $50 \%$ under the UV and SS light, respectively. In contrast, pure $\alpha$-S reduced the $\mathrm{MO}$ by only $14 \%$ and $6 \%$ under the same test conditions. For decoloring of $\mathrm{MO}$ by photocatalysis during the light illumination period, the half-time $\left(\mathrm{T}_{1 / 2}\right)$ can be determined from the MO reduction curves. Under the UV light, the $\mathrm{T}_{1 / 2}$ of MO for $\alpha-S$ was $883 \mathrm{~min}$, while the $\mathrm{T}_{1 / 2}$ for S/GR-3\% was only $122 \mathrm{~min}$. Similarly, the $\mathrm{T}_{1 / 2}$ decreased from $3100 \mathrm{~min}$ for $\alpha$-S to $436 \mathrm{~min}$ for S/GR-3\% under the SS light. 

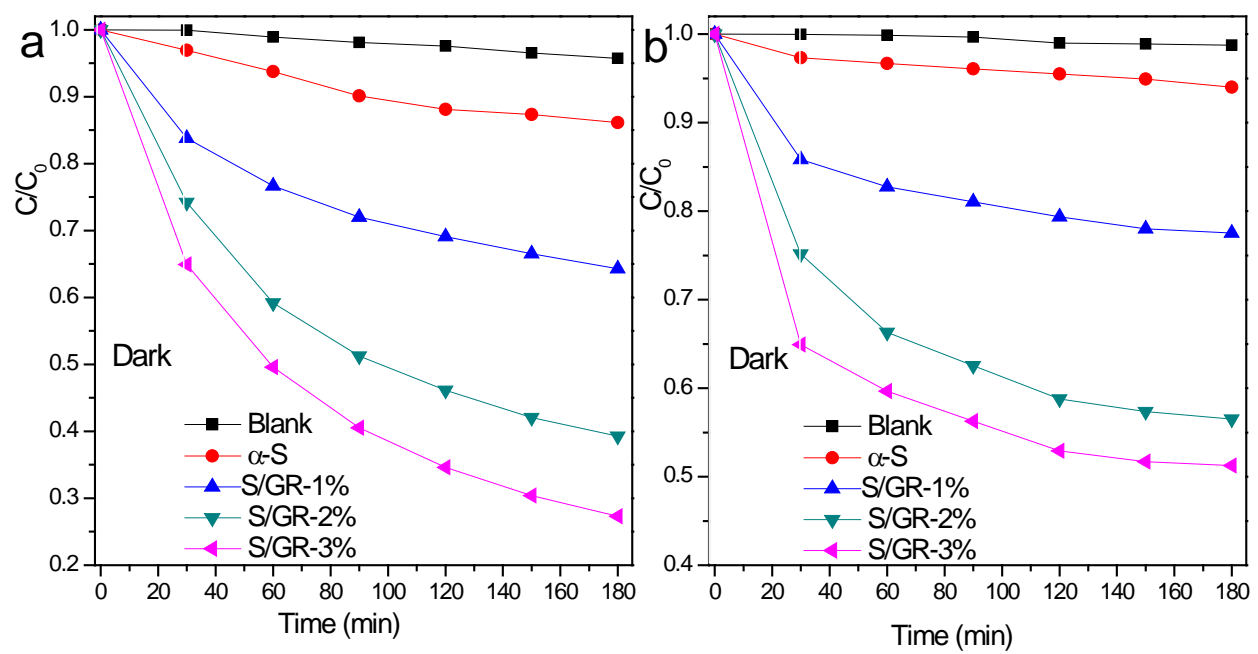

Figure 6 Degradation of methyl orange in the solutions under (a) UV light and (b) simulated solar light by $\alpha$-S and S/GR composites.

The role of GR in the photocatalytic $\mathrm{MO}$ degradation by the $\alpha$-S/GR composite is illustrated in Figure 7. MO molecules can be readily adsorbed by the aromatic regions of graphene via conjugation, which is beneficial to the subsequent MO degradation [18]. Under UV or SS light, irradiation of photosensitive $\alpha$-S results in electron excitation and electron-hole pairs. The graphene sheets act as an electron collector to transfer photo-generated electrons from $\alpha$-S to electron acceptors, e.g. dissolved oxygen, in the aqueous phase to facilitate the electron-hole separation. The holes can directly oxidize MO molecules adsorbed on the catalyst surface. Moreover, the holes may react with water (or hydroxyl) to form hydroxyl free radicals $(\cdot \mathrm{OH})$, which are a strong oxidant for $\mathrm{MO}$ decomposition [4]. The degradation of $\mathrm{MO}$ would lead to decoloration of the solution and produce $\mathrm{CO}_{2}, \mathrm{H}_{2} \mathrm{O}$, and intermediate products such as phenolic compounds and carboxylic acids. The major reaction steps in the photocatalytic process can be described by the following equations (1-6) [9,19].

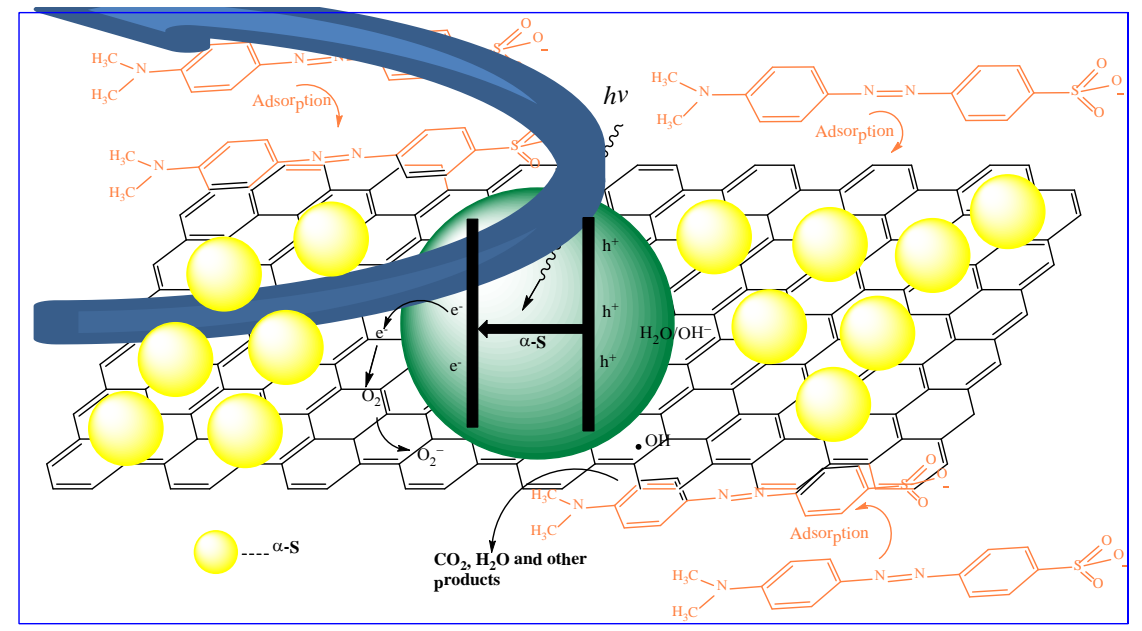

Figure 7 Schematics of the proposed reaction mechanism for the photocatalytic degradation of MO by the S/GR composite. 


$$
\begin{aligned}
& \alpha-\mathrm{S}+\mathrm{hv} \rightarrow \alpha-\mathrm{S}\left(\mathrm{e}^{-}+\mathrm{h}^{+}\right) \\
& \alpha-\mathrm{S}\left(\mathrm{e}^{-}\right)+\mathrm{GR} \rightarrow \alpha-\mathrm{S}+\mathrm{GR}\left(\mathrm{e}^{-}\right) \\
& \mathrm{GR}\left(\mathrm{e}^{-}\right)+1 / 2 \mathrm{O}_{2} \rightarrow \mathrm{GR}+\mathrm{O}_{2}^{-} \\
& \alpha-\mathrm{S}\left(\mathrm{h}^{+}\right)+\mathrm{MO} \rightarrow \mathrm{CO}_{2}+\mathrm{H}_{2} \mathrm{O}+\text { other products } \\
& \alpha-\mathrm{S}\left(\mathrm{h}^{+}\right)+\mathrm{OH}^{-} \rightarrow \alpha-\mathrm{S}+\cdot \mathrm{OH} \\
& \cdot \mathrm{OH}+\mathrm{MO} \rightarrow \mathrm{CO}_{2}+\mathrm{H}_{2} \mathrm{O}+\text { other products }
\end{aligned}
$$

\section{Conclusions}

The $\alpha$-S/GR composite, a novel metal-free photocatalyst, was synthesized using a facial one-pot, two-step hydrothermal method. Compared with pure $\alpha-S$, the new catalyst shows much enhanced photocatalytic activity for the degradation of $\mathrm{MO}$ under both UV and simulated solar light. The incorporation of GR greatly increases the hydrophilicity and adsorption capacity of $\alpha$-S. Moreover, the graphene sheets can function as electron collectors to facilitate the electron-hole separation, resulting in enhanced $\cdot \mathrm{OH}$ radical generation and $\mathrm{MO}$ degradation.

\section{Acknowledgements}

This research was supported by grants HKU714112E from the Research Grants Council (RGC) and SEG_HKU10 from the University Grants Committee (UGC) of the Government of Hong Kong SAR. The technical assistance of Mr. Keith C.H. Wong is highly appreciated.

\section{References}

[1] Fujishima, A. Electrochemical photolysis of water at a semiconductor electrode. Nature 1972, 238, 37-38.

[2] Chen, X. B.; Shen, S. H.; Guo, L. J.; Mao, S. S. Semiconductor-based photocatalytic hydrogen generation. Chem Rev 2010, 110, 6503-6570.

[3] Wang, F.; Ng, W. K. H.; Yu, J. C.; Zhu, H. J.; Li, C. H.; Zhang, L.; Liu, Z. F.; Li, Q. Red phosphorus: An elemental photocatalyst for hydrogen formation from water. Appl Catal B-Environ 2012, 111, 409-414.

[4] Liu, G.; Niu, P.; Yin, L. C.; Cheng, H. M. Alpha-sulfur crystals as a visible-light-active photocatalyst. J Am Chem Soc 2012, 134, 9070-9073.

[5] Wang, X. C.; Maeda, K.; Thomas, A.; Takanabe, K.; Xin, G.; Carlsson, J. M.; Domen, K.; Antonietti, M. A metal-free polymeric photocatalyst for hydrogen production from water under visible light. Nat Mater 2009, 8, 76-80.

[6] Novoselov, K. S.; Geim, A. K.; Morozov, S. V.; Jiang, D.; Zhang, Y.; Dubonos, S. V.; Grigorieva, I. V.; Firsov, A. A. Electric field effect in atomically thin carbon films. Science 2004, 306, 666-669.

[7] Huang, X.; Qi, X. Y.; Boey, F.; Zhang, H. Graphene-based composites. Chem Soc Rev 2012, 41, 666-686.

[8] Xiang, Q. J.; Yu, J. G.; Jaroniec, M. Synergetic effect of $\mathrm{MoS}_{2}$ and graphene as cocatalysts for enhanced photocatalytic $\mathrm{H}_{2}$ production activity of $\mathrm{TiO}_{2}$ nanoparticles. J Am Chem Soc 2012, 134, 6575-6578.

[9] Xiang, Q. J.; Yu, J. G.; Jaroniec, M. Graphene-based semiconductor photocatalysts. Chem Soc Rev 2012, 41, 782-796.

[10] An, X. Q.; Yu, J. C. Graphene-based photocatalytic composites. Rsc Adv 2011, 1, 1426-1434.

[11] Du, A. J.; Sanvito, S.; Li, Z.; Wang, D. W.; Jiao, Y.; Liao, T.; Sun, Q.; Ng, Y. H.; Zhu, Z. H.; Amal, R.; Smith, S. C. Hybrid graphene and graphitic carbon nitride nanocomposite: Gap opening, electron-hole puddle, interfacial charge transfer, and enhanced visible light response. J Am Chem Soc 2012, 134, 4393-4397.

[12] Hummers Jr, W. S.; Offeman, R. E. Preparation of graphitic oxide. J Am Chem Soc 1958, 80, 1339-1339.

[13] Paredes, J. I.; Villar-Rodil, S.; Martinez-Alonso, A.; Tascon, J. M. D. Graphene oxide dispersions in organic solvents. Langmuir 2008, 24, 10560-10564.

[14] Park, M. S.; Yu, J. S.; Kim, K. J.; Jeong, G.; Kim, J. H.; Jo, Y. N.; Hwang, U.; Kang, S.; Woo, T.; Kim, Y. J. One-step synthesis of a sulfur-impregnated graphene cathode for lithium-sulfur batteries. Phys Chem Chem Phys 2012, 14, 6796-6804.

[15] Fernandez-Merino, M. J.; Guardia, L.; Paredes, J. I.; 
Villar-Rodil, S.; Solis-Fernandez, P.; Martinez-Alonso, A.; Tascon, J. M. D. Vitamin C is an ideal substitute for hydrazine in the reduction of graphene oxide suspensions. J Phys Chem C 2010, 114, 6426-6432.

[16] Zhang, Y. H.; Tang, Z. R.; Fu, X. Z.; Xu, Y. J. $\mathrm{TiO}_{2}$-Graphene Nanocomposites for Gas-phase photocatalytic degradation of volatile aromatic pollutant: Is $\mathrm{TiO}_{2}$-graphene truly different from other $\mathrm{TiO}_{2}$-carbon composite materials? Acs Nano 2010, 4, 7303-7314.

[17] Nam, W.; Kim, J.; Han, G. Y. Photocatalytic oxidation of methyl orange in a three-phase fluidized bed reactor. Chemosphere 2002, 47, 1019-1024.
[18] Zhang, H.; Lv, X. J.; Li, Y. M.; Wang, Y.; Li, J. H. P25-graphene composite as a high performance photocatalyst. Acs Nano 2010, 4, 380-386.

[19]Liu, J. C.; Bai, H. W.; Wang, Y. J.; Liu, Z. Y.; Zhang, X. W.; Sun, D. D. Self-assembling $\mathrm{TiO}_{2}$ nanorods on large graphene oxide sheets at a two-phase interface and their anti-recombination in photocatalytic applications. Adv Funct Mater 2010, 20, 4175-4181. 